\title{
Developments in flexible endoscopic surgery: a review
}

This article was published in the following Dove Press journal:

Clinical and Experimental Gastroenterology

18 December 2014

Number of times this article has been viewed

\author{
Hubertus Feussner ${ }^{1}$ \\ Valentin Becker ${ }^{2}$ \\ Margit Bauer' \\ Michael Kranzfelder' \\ Rebekka Schirren' \\ Tim Lüth ${ }^{3}$ \\ Alexander Meining ${ }^{2}$ \\ Dirk Wilhelm' \\ 'Department of Surgery, ${ }^{2} 2 \mathrm{nd}$ \\ Medical Department, ${ }^{3}$ Institute of \\ Microtechnology and Medical Device \\ Technology, Klinikum rechts der Isar, \\ Technische Universität München, \\ Germany
}

Correspondence: Hubertus Feussner Chirurgische Klinik, Klinikum rechts der Isar, Technische Universität München, Ismaninger Str 22, 81675 Munich, Germany

Tel +498941402030

Fax +4989 41406030

Email hubertus.feussner@tum.de
Abstract: Flexible endoscopy is increasingly developing into a therapeutic instead of a purely diagnostic discipline. Improved visualization makes early lesions easily detectable and allows us to decide ad hoc on the required treatment. Deep enteroscopy allows the exploration of even the small bowel - for long a "white spot" for gastrointestinal endoscopy - and to perform direct treatment. Endoscopic submucosal dissection is a considerable step forward in oncologically correct endoscopic treatment of (early) malignant lesions. Though still technically challenging, it is increasingly facilitated by new manipulation techniques and tools that are being steadily optimized. Closure of wall defects and hemostasis could be improved significantly. Even the anatomy beyond the gastrointestinal wall is being explored by the therapeutic use of endoluminal ultrasound. Endosonographic-guided surgery is not only a suitable fallback solution if conventional endoscopic retrograde cholangiopancreatography fails, but even makes necrosectomy procedures, abscess drainage, and neurolysis feasible for the endoscopist. Newly developed endoscopic approaches aim at formerly distinctive surgical domains like gastroesophageal reflux disease, appendicitis, and cholecystitis. Combined endoscopic/laparoscopic interventional techniques could become the harbingers of natural orifice transluminal endoscopic surgery, whereas pure natural orifice transluminal endoscopic surgery is currently still in its beginnings.

Keywords: flexible endoscopic surgery, endoscopic ultrasound, advanced techniques, natural orifice transluminal endoscopic surgery

\section{Introduction}

A few other disciplines have had a more dynamic development in short-term history of medicine than flexible endoscopic surgery. In the beginning the flexible gastroscope or colonoscope were simply diagnostic tools, but soon, with the introduction of endoscopic papillotomy and choledochal stone extraction, a therapeutic arm was added. Gradually, additional interventional techniques were introduced into clinical practice. Endoscopic polypectomy and mucosal resection were able to replace surgical resection leading to a major step ahead in trauma reduction. Currently, even more sophisticated endoscopic surgical maneuvers are on the threshold of becoming the clinical standard. This short overview delineates the current state of the art and promising new developments.

\section{Technical breakthroughs Image enhancement}

Prior to treatment, pathological findings have to be detected. It has to be assumed that many early lesions are overseen due to the shortcomings of standard white light endoscopy. Dye techniques are used to improve the detection rate of precancers and 
early cancers, but the use of dye solutions is cumbersome and not very reliable. New optical and/or electronic methods are currently in experimental or clinical evaluation that could help to improve the detection rate: narrow-band imaging, autofluorescence imaging, confocal laser microscopy, and optimal band imaging.

Though the techniques differ, the aim is similar in all cases: contrast enhancement between the epithelial surface and the subjacent vascular pattern (Figure 1). Even early cancers have abundant blood vessels due to angiogenesis. Therefore, the recognition of atypical capillary beds supports the diagnosis of a neoplastic lesion and allows, for example, the differentiation between an adenomatous polyp, which has to be resected, and inflammative or hyperplastic lesions - without a biopsy. Each of these innovative approaches has specific strengths and weaknesses, and none of them have already become clinical standard, but there is no doubt that the identification of pathological abnormalities will soon be significantly facilitated. ${ }^{1}$

In a recent meta-analysis, Song et al confirmed the value of narrow-band imaging to detect dysplasia in Barrett's esophagus, ${ }^{2}$ whereas confocal laser microscopy and autofluorescence imaging are not yet as reliable in these instances. ${ }^{3,4}$ However, development is fast and the early detection rate is growing.

\section{Enteroscopy}

The endoscopic diagnosis and treatment of small bowel disorders has long been extremely difficult because of the length and mobility of the small intestine. Accordingly, the assessment

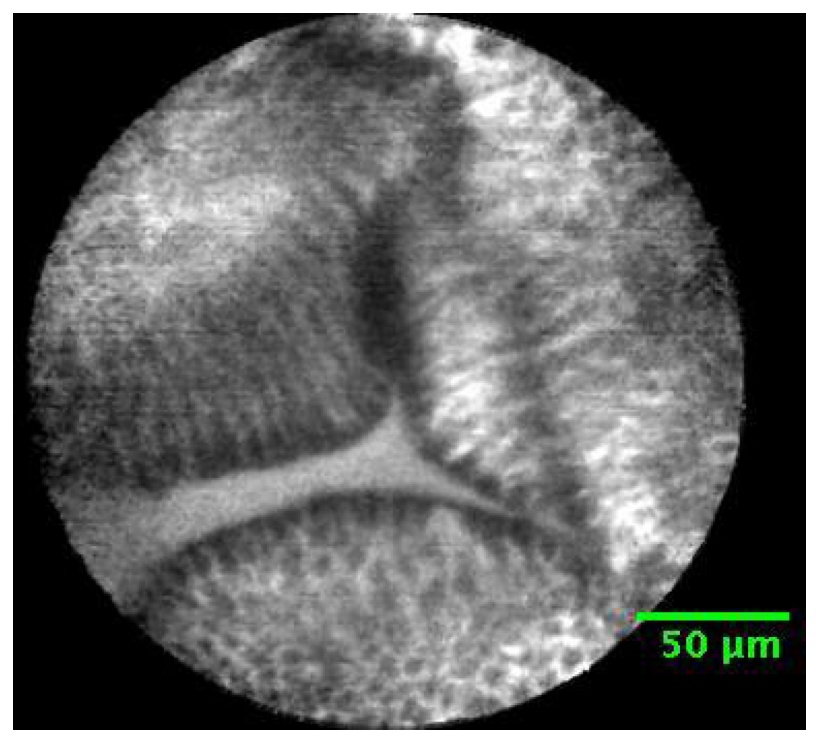

Figure I Confocal laser image of benign Barrett's esophagus. Note: Individual cells can be identified. of small intestine disorders remained the domain of radiologists.

With the advent of capsule endoscopy about 15 years ago, the diagnostic gap could be closed in gastroenterology, but a therapeutic arm was only achieved with the introduction of different techniques of deep enteroscopy. In 2001, double balloon enteroscopy was first reported, soon followed by singleballoon enteroscopy and spiral enteroscopy. The indications for either technique are similar. The most common one is the detection and treatment of obscure intestinal bleeding, followed by the assessment of inflammative mucosal lesions and the acquisition of biopsies or the removal of small tumors (Figure 2).

Device-assisted enteroscopy - the general term for the different variations of deep enteroscopy techniques - recently turned out to be a valuable help in the case of difficult endoscopic retrograde cholangiopancreatography (ERCP). In patients with a history of reconstructive bile duct surgery, it is often impossible to pass the limb to the bilioenteric anastomosis or to reach the papilla with the conventional ERCP endoscope. Device-assisted enteroscopy for ERCP is significantly more successful. ${ }^{5}$

\section{Endoscopic mucosal and submucosal resection}

As compared to endoscopic mucosal resection (EMR), endoscopic submucosal dissection (ESD) is increasingly gaining popularity since it enables achievement of en bloc and complete resection of larger lesions. En bloc resection

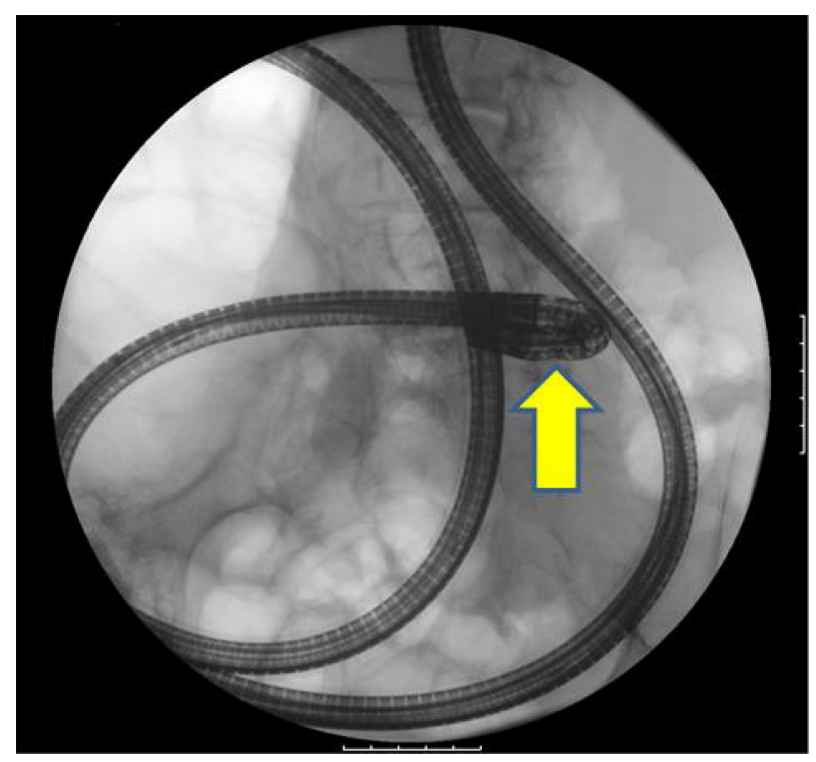

Figure 2 Plain abdominal $X$-ray with an enteroscope in situ.

Note: The balloon endoscope is clearly visible with its tip (arrow) deep in the small bowel (balloon not visible). 
in EMR is limited to lesions up to $20 \mathrm{~mm}$, and the technique can be divided into injection-, cap- and ligation-associated procedures. ${ }^{6}$ For cap-assisted EMR, the respective lesion is lifted by submucosal injection from the muscularis propria. Suction is applied to retract the lesion into a transparent cap at the tip of the endoscope. Resection is performed with a previously placed electrocautery snare. ESD has been developed in Japan to resect large lesions $(>20 \mathrm{~mm})$ in early cancer with higher en bloc resection rates or to gain accurate histological diagnosis. ${ }^{7}$ However, the procedure is one of the most complex endoscopic procedures and still challenging because of long procedure time and higher risk of complications including bleeding and perforation. For both complications, the over-the-scope clip (OTSC) system offers an effective treatment. ${ }^{8}$ ESD is usually used in early gastric cancer, and neoplastic lesions in the colon and esophagus. The technique comprises multiple steps. First, the respective lesion is marked with coagulation dots to identify the lesion clearly during the entire endoscopic procedure. Before circumferential incision outside the dots with a specialized knife, lesions are lifted from muscle layer by injection of several milliliters of solution into the submucosal layer. Thereafter, the submucosal connective tissue is dissected using a specific knife (Figure 3). If necessary, the remaining lesion can be removed using a standard polypectomy snare and visible vessels are coagulated with hemostatic forceps. ${ }^{9}$ Long-term studies show 5-year overall survival rates in superficial esophageal squamous carcinoma between $90.5 \%$ and $70.8 \%$ mostly depending on the depth of tumor invasion. ${ }^{10}$

Today, study groups focus on improvement of different working steps to make ESD more secure and faster. Different injection solutions for lifting the mucosa have been evaluated. Mucosal lifting isolates the mucosa and protects deeper layers from injury or perforation. In a pig model, photocrosslinkable chitosan hydrogel, which can be converted by ultraviolet (UV) irradiation in insoluble hydrogel, permits a long-lasting elevation of the mucosa without bleeding or perforation. ${ }^{11}$ Another study group could demonstrate similar effects in vitro for autologous blood injection, which is always available and very economical. ${ }^{12}$ Another research focus is on the development of new endoscopic instruments for ESD. Meining et al $^{13}$ presented a new device ready to perform all working steps with the same instrument. The prototype is based on standard forceps. By performing incision, dissection, and coagulation of vessels with the same instrument, working time might be reduced, and the special technique of

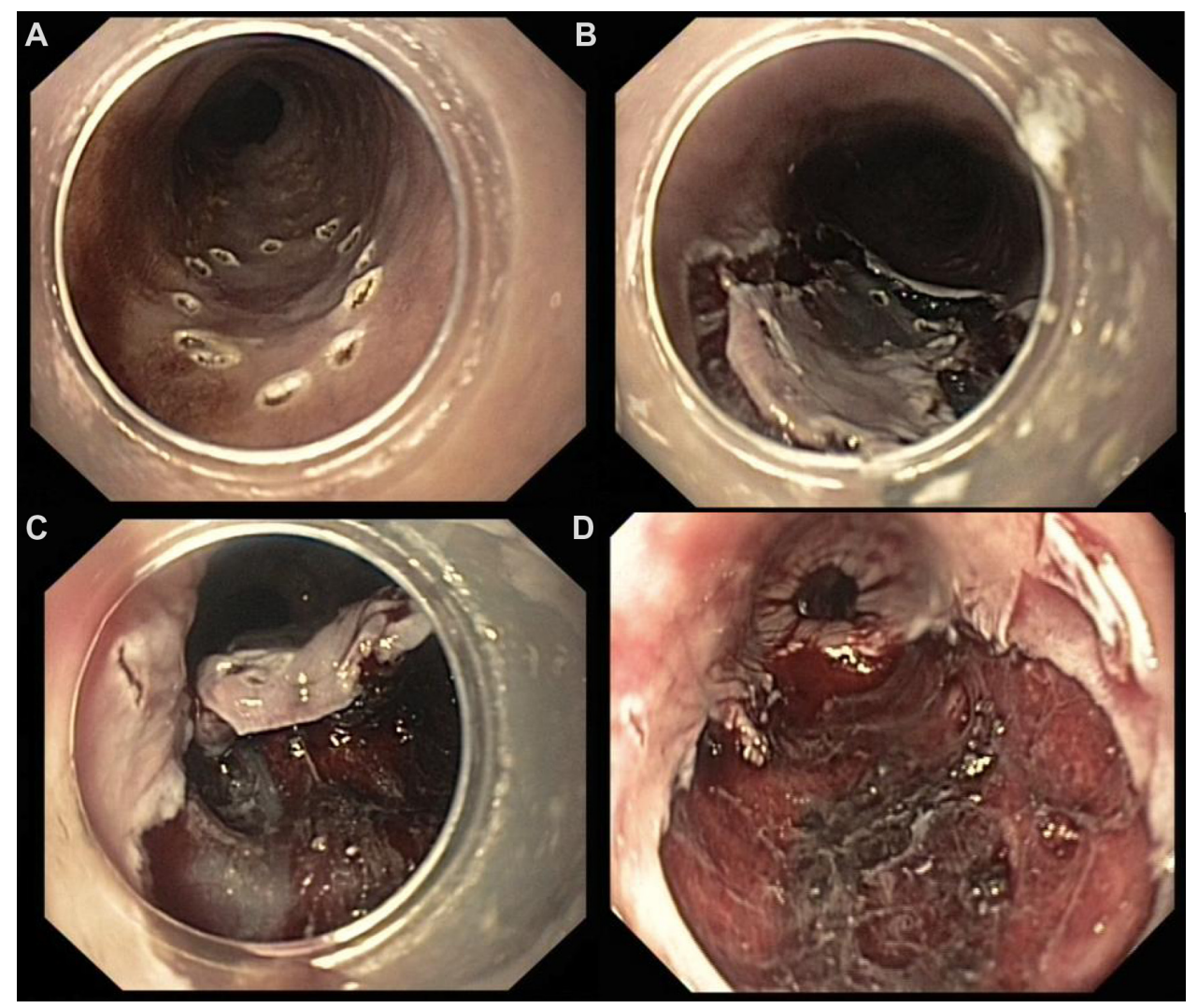

Figure 3 Four steps of endoscopic submucosal dissection: marking of lesion (A), mucosal incision (B), submucosal dissection (C), and the final result after en bloc resection (D). 
lifting the submucosal fibers might reduce perforation rate in future. ${ }^{13}$ In the first human feasibility study, a Japanese study group recently presented a new scissors-type electrosurgical knife for better durability and easy use. The single-use electrosurgical incision forceps was designed with a special tip with insulated ceramic covered blade. Therefore, the device cuts only the grasped material, which might reduce perforation rate. ${ }^{14}$ For better countertraction, various methods were presented in the last few years. Some authors use simple distance caps at the tip of the endoscope, and others use double-channel endoscopes or intraluminal traction systems. Recently, a novel traction method using an over-the-scope steerable grasper was presented that allows optimal dissection plane. The first preclinical results are promising. ${ }^{15}$ Still the effects are not optimal, and improvement of traction techniques are necessary. However, in future, all the continuous improvements in ESD will transform this technique into a standard, widely available endoscopic therapy.

\section{Closure of perforations and full wall resection}

A few years ago, a perforation of the colonic, gastric, or esophageal wall induced by the endoscopist was a debacle requiring urgent surgical revision. Today, at least two new tools exist to manage these types of lesions endoscopically. The development of both of them was significantly promoted by the oncoming idea of natural orifice transluminal endoscopic surgery (NOTES).

\section{Anchoring technique}

The anchoring technique is based upon the use of two tiny needles connected to a long thread. Each of these two anchoring elements is fixed to one edge of the lesion. In the next step, a bolting element is advanced approximating the two anchoring elements as close as required. Thus, the two edges are compressed, and the defect of the intestinal wall is closed. Although this concept is proven to be safe and reliable, ${ }^{16,17}$ it is not yet available commercially.

\section{OTSC}

Another revolutionary approach that could already be introduced into clinic routine is the so called OTSC. The system can be used for treatment of gastrointestinal (GI) bleeding, perforations, leakages, fistulas, and closure of NOTES accesses. It consists of an application cap including the clip that is mounted on the tip of the endoscope. Clips are released by using a hand wheel operated by the endoscopist. There are three different cap sizes (11 mm, $12 \mathrm{~mm}$, and $14 \mathrm{~mm}$ ) and three different shapes of teeth (blunt teeth; spiked teeth; and longer, pointed teeth) available for different indications. The clip is made of nitinol, a magnetic resonance imaging (MRI)-safe and biocompatible material, and effects a wall compression of 8.9 N. ${ }^{18}$ Two additional instruments (OTSC Anchor and OTSC Twin Grasper) are available as application aids.

The OTSC system was extensively tested in a number of preclinical trials. In an acute porcine model of colonic perforations, open surgical repair and endoscopic closure using the OTSC system's complete sealing of colostomy, were performed. Burst pressure in leak test and total procedure time were comparable in both groups. ${ }^{19}$ There are also an increasing number of trials evaluating the OTSC system for closing NOTES access sites, or endoscopic full-thickness resection. In combination with the twin grasper device to achieve inversion of the edges, the OTSC system provides a reliable and fast option for closure of transmural defects (Figure 4). ${ }^{20}$

So far, there are only a limited number of prospective randomized trials evaluating the OTSC systems in humans but a rapidly increasing number of small case series. In a prospective case series, Gubler and Bauerfeind successfully treated 13 of 14 patients with perforations up to $30 \mathrm{~mm}$ in the upper GI tract with an OTSC clip. ${ }^{21}$ Similar results after iatrogenic perforations in endoscopic resections of gastric subepithelial masses were reported in another prospective series. ${ }^{22}$ Case reports show promising results in closing enterocutaneous fistula or postoperative leakages. ${ }^{23,24}$ Most of the clips persist in situ at follow-up examination. If necessary, it is also possible to remove clips endoscopically. In a preliminary study of eleven patients, removal of the OTSC clip was possible in $91 \%$ of the patients using a prototype of a bipolar cutting device. ${ }^{25}$ From the current point of view, the OTSC system is a highly promising endoscopic device with the lack of high-quality prospective randomized trials.

\section{Endoscopic hemostasis}

According to the type, size, and location of the bleeding lesion, a variety of tools is available today. Injection techniques using epinephrine, ethanol, or hypertonic saline are frequently applied as well as thermocoagulation with contact or noncontact devices.

Mechanical forms of hemostasis include hemoclips and/ or detachable snares. A new polysaccharide hemostatic system (EndoClot Plus; Santa Clara, CA, USA) was recently developed. By simple spray application, bleeding can be controlled effectively. ${ }^{26}$ Overall, technical development has led to a significant improvement in the interventional endoscopic 

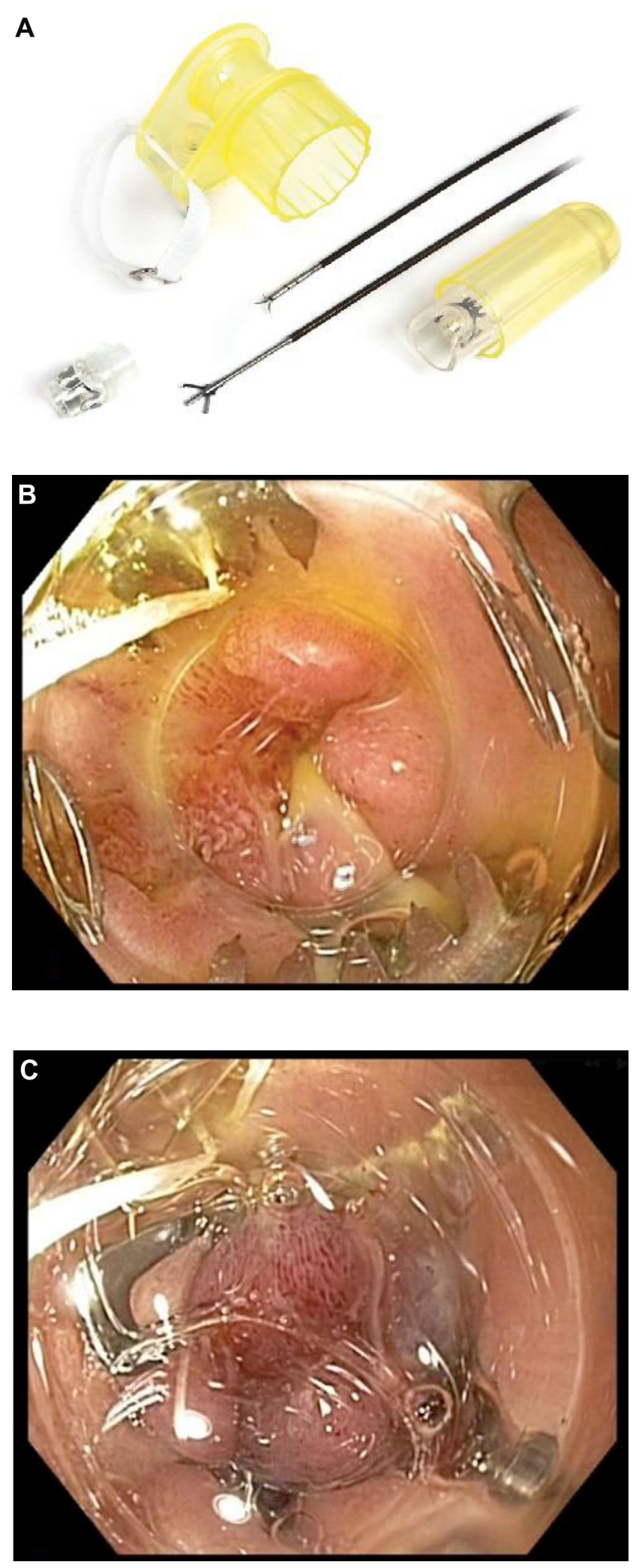

Figure 4 Application of the over-the-scope clip (OTSC) clip.

Notes: (A) OTSC: The clip (left down) is transported via the application system in yellow into the Gl tract. The system is mounted on the tip of a normal endoscope. Two auxiliary instruments are available to pull the tissue into the clip. (B) Clinical application. The open lesion as seen through an over cap. (C) Clip fired and lesion occluded.

Abbreviation: $\mathrm{Gl}$, gastrointestinal. management of GI-bleedings, which has drastically reduced the number of emergency surgeries.

\section{Tunneling techniques}

Though new techniques of wound closure are available today as mentioned above, an indirect access to submucosal structures (or, in the case of NOTES, the abdominal cavity) could be superior to a direct incision at the site of the lesion (or the entrance point in NOTES). The incision of the mucosa is located at some distance from the former area of interest. The creation of a submucosal route tunnel is facilitated by preparing a linear submucosal edema. If a NOTES intervention is considered, the tunneling technique is continued by the perforation of the muscular layer and the serosa at the far end of the tunnel, thus creating a Z-shaped valve-like access route (Figure 5).

In the case of peroral endoscopic myotomy (POEM) of the esophagocardiac junction, a mucosa-protected transection of the muscular layer is feasible. The so-called "submucosal tunneling and endoscopic resection" technique is designed to excise tumors beneath the mucosa. After resection, the tumor is removed via the tunnel..$^{27-30}$

Tunneling techniques are particularly applicable in the esophagus and stomach.

\section{Sonographically guided endoscopic surgery}

The endoluminal view provided by the flexible endoscope can be augmented by simultaneous endoscopic ultrasonography (EUS). Originally a purely diagnostic procedure, EUS has now evolved as a therapeutic tool as well.

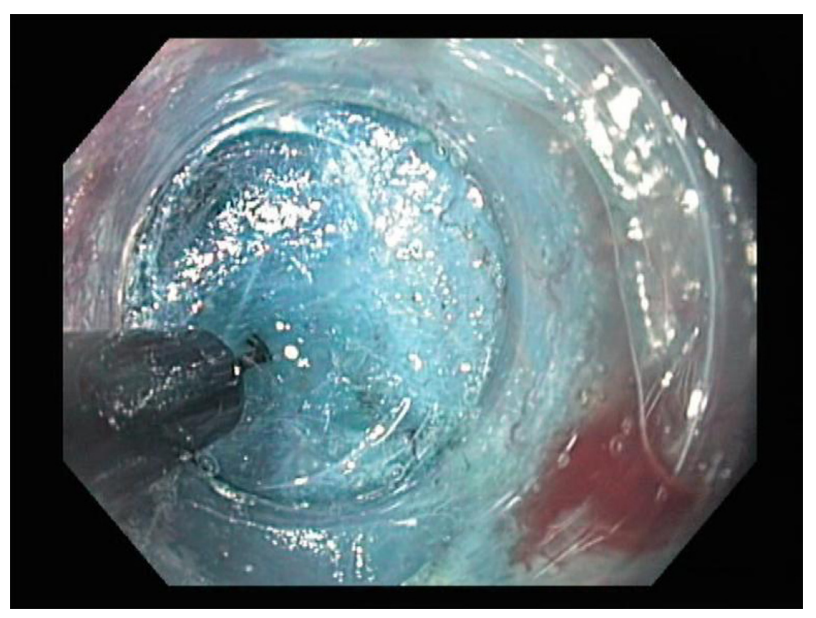

Figure 5 Tunneling technique.

Notes: The endoscope is introduced into the submucosal space after injection of indigo-stained saline solution. A hook knife is used for dissection of submucosal fibers. 
Today, ERCP is still the first-line option for the drainage of the biliary tree and is successful in $85 \%-98 \%$ of cases. However, cannulation may become impossible due to anatomical variations or tumor infiltration of the papilla. In these instances, percutaneous transhepatic biliary drainage (PTCD) or surgery is common. In recent years, EUS-guided cholangiopancreatography became a successful and safe alternative to percutaneous or surgical interventions. The first case series was reported by Wiersema et al in $1996 .{ }^{31}$ EUS-guided cholangiopancreatography can be performed immediately, as soon as it becomes clear that ERCP is impossible. As opposed to PTCD, an internal drainage is achieved which is considerably superior in regard to the quality of life of the patient (Figure 6).

EUS-guided bile duct drainage is performed utilizing either the rendezvous technique or by creating a direct tract from the bile tree to the stomach or duodenum. Published data are still limited in number, but the overall success rate of EUS-guided bile duct drainage is high and major complications such as perforation or bleeding requiring surgery are uncommon. ${ }^{32}$

Beyond EUS-bile duct interventions, other therapeutic options are EUS-guided celiac plexus blocks, celiac plexus neurolysis, and drainage of fluid pancreatic and pelvic collections.

Though EUS-guided therapies are evidently more prone to complications than diagnostic EUS, they compare favorably with surgical interventions..$^{33}$

\section{Endoscopic pancreatic necrosectomy}

Not more than a decade ago, necrosectomy due to acute pancreatitis was a domain of conventional surgery.

Infection of pancreatic necrosis is a life-threatening complication during the course of acute pancreatitis. In critically ill patients, surgical or extended endoscopic interventions are associated with high morbidity and mortality. ${ }^{34}$ Therefore, in the

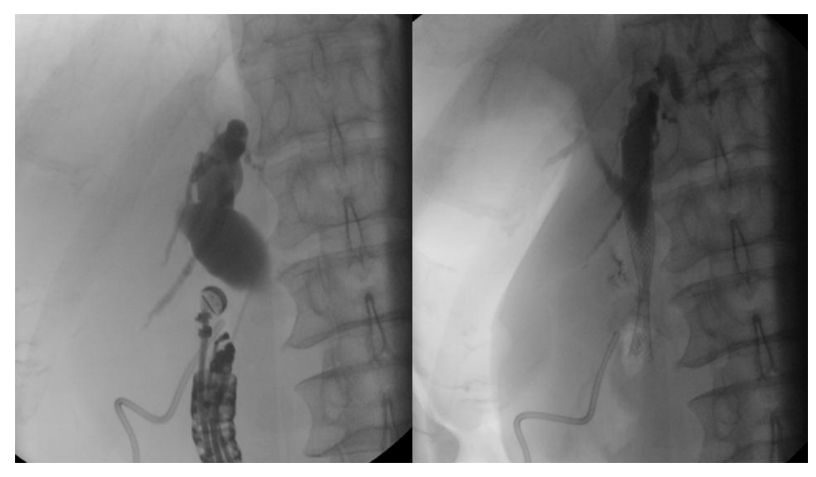

Figure 6 Endosonographically assisted endoscopy.

Note: EUS-guided puncture of inaccessible common bile duct and subsequent placements of a self-expanding metal stent through bulbocholedochostomy. Abbreviation: EUS, endoscopic ultrasonography. last few years, there has been a therapeutic shift from invasive surgical procedures to minimally invasive endoscopic procedures including ultrasound-guided drainage and stent application. ${ }^{35}$ However, percutaneous or endoscopic procedures using small drainage catheters lacking in removal of necrotic material, and endoscopic debridement is necessary. Our study group presented a strategy combining percutaneous and transgastric drainage with continuous high-volume lavage for treatment of extended necrosis and liquid collections in a series of patients with severe acute pancreatitis, which was effective to remove debris. However, several endoscopic interventions for stent replacement were necessary. ${ }^{34}$ There is also a rising number of studies using endoscopic transmural necrosectomy for walledoff pancreatic necrosis. Regular or pediatric gastroscopes with snares, basket catheters, and alligator forceps are used to remove solid and purulent necrotic material. Additionally, fully covered metal stents with bilateral anchor flanges can appose nonadherent lumens (AXIOS, $15 \mathrm{~mm} \times 10 \mathrm{~mm}$; Xlumena, Mountain View, CA, USA) and improve removal of debris. ${ }^{36}$ Ross et al reported favorable long-term results of percutaneous/endoscopic drainage with avoidance of pancreaticocutaneous fistulas, surgical necrosectomy, or major procedure-related adverse events. ${ }^{37}$

\section{Endoscopic stenting}

Endoscopic placement of self-expandable stents to overcome obstructions of the GI tract has emerged as a valuable therapeutic option in the case of benign or malignant lesions. Whenever applicable, stenting is superior to surgical treatment of hepatobiliary strictures. Surgical bilioenteric anastomosis is associated with a comparatively high morbidity and even mortality, and requires hospitalization, whereas stenting can be performed as an outpatient procedure. Long-term stenting of the bile duct may avoid revision surgery after bile duct lesions due to cholecystectomy. ${ }^{38}$ In the palliative treatment of esophageal cancer, esophageal stenting completely replaced surgical bypass operations (Figure 7). Malignant gastric outlet obstruction ${ }^{39}$ and colonic stenosis could be reasonable indications as well. The ability to take food orally can be regained in about $90 \%$ of patients,${ }^{40}$ making it slightly less effective than gastrojejunostomy but by far, less complicated. ${ }^{41,42}$

Table 1 gives an overview of the most important innovations.

\section{Endoscopic approaches to surgical indications Antireflux interventions}

In the beginning of this millennium, endoscopic surgeons all over the world tried to find endoluminal solutions 

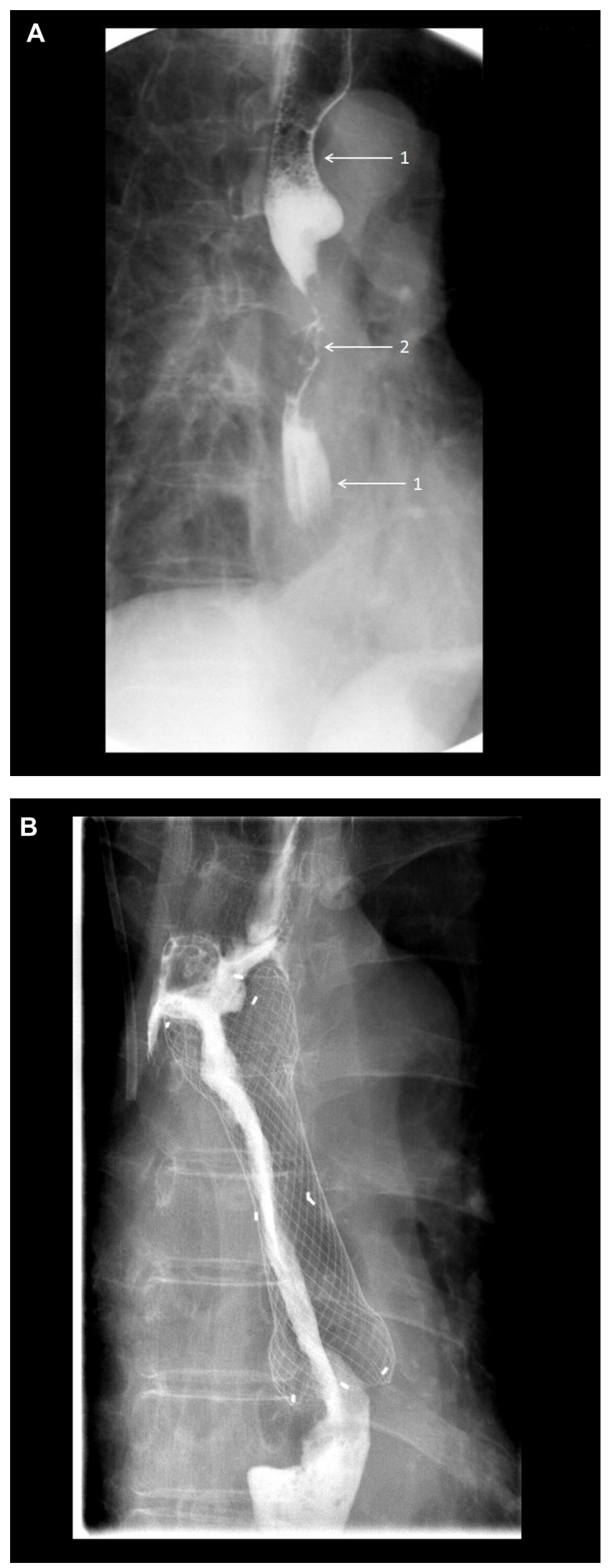

Figure 7 Subtotal occlusion of the esophagus due to squamous cell carcinoma. Notes: (A) Barium swallow: I, normal esophagus and 2, subtotal occlusion due to esophageal carcinoma. The patient is unable to eat. (B) Barium swallow control after stent insertion: The contrast medium passes unimpaired. Food intake is possible again.
Table I Technical innovations and clinical applications

\begin{tabular}{lll}
\hline Technical innovation & Application & Solutions \\
\hline Visualization & $\begin{array}{l}\text { Detection of early } \\
\text { cancer }\end{array}$ & $\begin{array}{l}\text { Narrow-band imaging, } \\
\text { etc }\end{array}$ \\
Tissue approximation & Wound closure & $\begin{array}{l}\text { Eg, OTSC, anchoring } \\
\text { techniques }\end{array}$ \\
Hemostasis & Bleeding & Hemoclips, detachable \\
Sonographically assisted & Treatment of biliary & EUares, EndoClot \\
endoscopic procedures & strictures, pancreatic & drainage, transgastric \\
& necrosectomy & necrosectomy \\
Stenting & Reopening of & Esophageal, biliary, \\
Platforms & strictures & and colonic stents \\
& Intra-abdominal & Eg, Master, \\
& surgery for monoport & Anubiscope, \\
& and NOTES & EndoSamurai \\
\hline
\end{tabular}

Abbreviations: EUS, endoscopic ultrasonography; NOTES, natural orifice transluminal endoscopic surgery; OTSC, over-the-scope clip.

for the treatment of gastroesophageal reflux disease. Retrospectively, the range of different approaches that were developed is admirable. Sphincter augmentation was attempted using injection techniques (Enteryx, Gatekeeper), electrothermal treatment (Stretta), and various suturing or riveting techniques. The most promising attempts were based on suturing techniques to restore the angle of His, such as the EndoCinch or the EsophyX. Unfortunately, none of the first or second generation endoluminal approaches passed the test of time, ${ }^{43-45}$ and most of the companies vanished from the market due to poor financial performance. ${ }^{46}$ "The search for the holy grail for incisionless endoscopic surgery is a journey littered with failed devices, procedures, and bankrupt companies". ${ }^{44}$

Recently, a third generation endoluminal antireflux system appeared on the market. The GerdX is a more advanced version of the former suturing systems. Besides being more ergonomically designed, a new suturing principle could hopefully improve the long-term efficiency of this type of endoluminal sphincter augmentation (Figure 8). The first experiences are promising, but the real value of endoluminal procedures has to be shown in the long-term follow-up.

\section{Appendicitis, cholecystitis}

Since acute appendicitis is caused by luminal obstruction, endoscopic treatment consists of dilatation or stenting of the appendix to provide sufficient drainage: endoscopic retrograde appendicostomy. In the first clinical series, the procedure was successful in over $90 \%$ of cases. ${ }^{47} \mathrm{~A}$ similar concept was also tried out in the treatment of acute cholecystitis utilizing an internal drainage. 

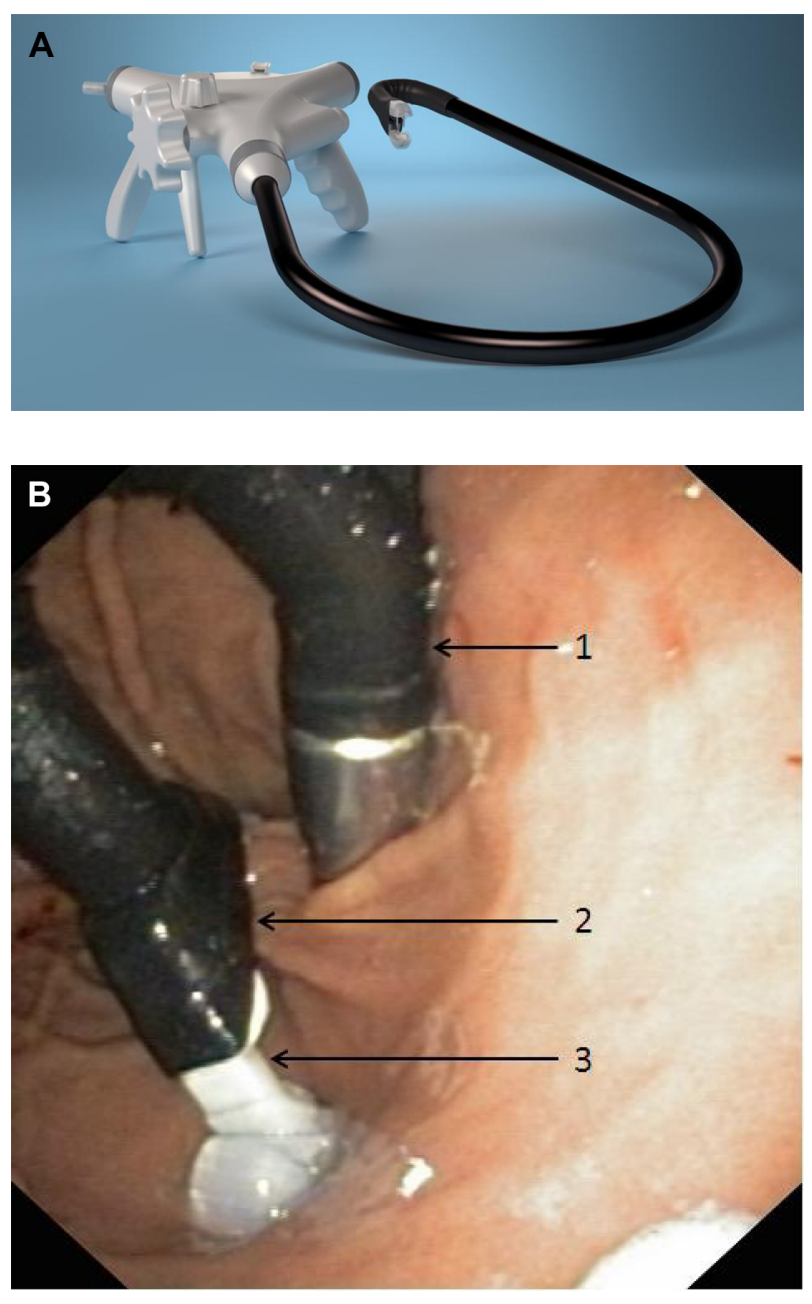

Figure 8 GerdX endoluminal antireflux system.

Notes: (A) GerdX system. (B) Endoscopic view of the gastric entrance in retroflexion: I, the system entering the stomach from the esophagus; 2, the maximally bent tip with its two arms to grasp the tissue; and 3, on this image, only one arm is visible.

\section{Hybrid procedures}

Despite numerous advances in endoscopic surgery, some lesions of the GI tract are still too difficult or too dangerous for an endoluminal approach. They might be too difficult to access or the risk of perforation is too high. In these cases, surgical therapy is required, either in the form of a laparoscopic wedge or a segmental resection or even by an open approach. Recently, it could be shown that simultaneous laparoscopic support could be helpful in these instances to enable endoscopists to treat pathological findings which are, a priori, not suitable for an endoluminal treatment (Figure 9). ${ }^{48,49}$

Using the so called laparoscopically assisted endoscopic resection technique, the lesion can be presented to the endoscopist in a way to enable him to now remove it by means of a snare or needle dissection. By pushing the tumor into the lumen or stretching the wall using graspers - graspers to

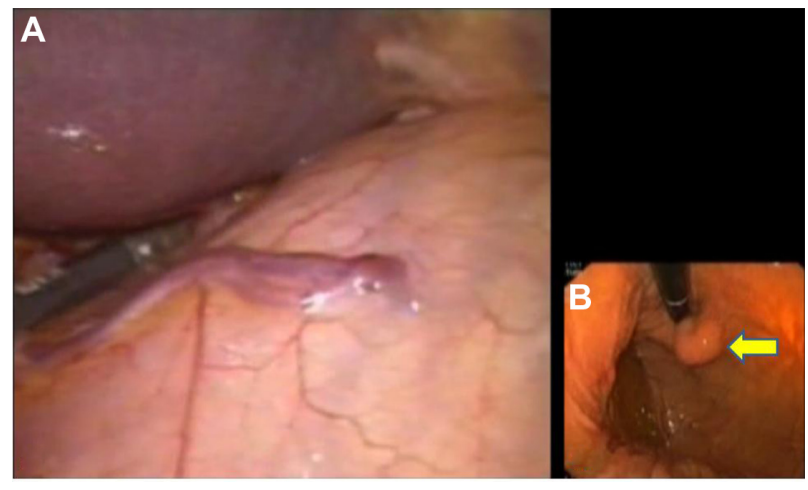

Figure 9 Combined laparoscopic/endoscopic intervention.

Notes: (A) Laparoscopic view of the anterior gastric wall. Somewhere beyond the gastric wall, a tumor is present, but its exact localization is impossible. (B) A look from within (flexible endoscopy). By simultaneous flexible endoscopy, the tumor site can be clearly identified.

eliminate folds - exposition of the tumor site can be improved significantly.

In the case of an intended full-thickness resection or a perforation, endoluminal closure is performed under laparoscopic control. Endoluminal instillation of dye indicates leaks, if present. If necessary, a leak can be easily closed by the laparoscopist by stapler application or by suturing. Hybrid procedures are particularly useful in the case of gastric or colonic lesions.

If laparoscopically assisted endoscopic resection is not applicable, two additional procedures are available: endoscopically assisted wedge resection (EAWR) or endoscopically assisted transluminal resection (EATR).

\section{EAWR}

If lesions are favorably located at the anterior gastric wall, the greater curvature, or the antimesocolic circumference of the colon, wedge resection using staplers can be applied. After exact localization of the tumor by the endoscopist, the surgeon elevates the respective part of the GI wall that carries the lesion, which can be done either by grasping the wall with automatic forceps, or by the use of one or more elevation sutures inserted through the abdominal wall. "Towing" the tumor site (the so called lesion lift method), the endoscopist evaluates from within whether the target site has been hit. If so, it is excised using the linear stapler. From the endoluminal side, the endoscopist may verify now that no relevant stricture was produced and that there is no leakage.

\section{EATR}

Lesions of the posterior gastric wall or of the mesocolic side of the colon are not suitable for wedge resection. In these cases, EATR is a good alternative. In the first step, the endoscopist demonstrates the exact site of the tumor to enable the 
laparoscopist to find the optimal entry point into the lumen. Diaphanoscopy is used in order to avoid lesions of major vessels. After incision of the anterior wall, the lesion is exposed and elevated by sutures and resected by application of one or more linear stapler applications. After revision of the posterior wall stapler line, the entry point on the anterior aspect of the stomach or colon is closed by suturing or again by linear stapler application. Again the suture lines are checked for bleeding and leakproofness by the endoscopist.

It has to be pointed out that hybrid surgery requires considerable additional organizational, personal, and operative expenses. Nevertheless, the convincing results in trauma reduction led to a growing popularity (Table 2 ).

A variant of hybrid surgery is the so called safety laparoscopy during NOTES procedures. The NOTES procedure is carried out under laparoscopic surveillance to prove successful removal of the lesion and a reliable closure of the entry site. ${ }^{50}$ Currently most NOTES trials are approved by the ethical committees only under the precondition of simultaneous safety laparoscopy.

\section{Natural orifice transluminal endoscopic surgery}

About 10 years ago, a revolutionary idea evolved in interventional medicine: surgery without scars, or scarless surgery. The idea is to enter the body via natural orifices (mouth, rectum, urethra, vagina) and to leave the GI, vaginal, or urological lumen by an incision to penetrate the abdominal cavity and then to perform therapeutic manipulations as usually performed in laparoscopic surgery. The idea is appealing since internal entry sites are invisible and do not cause pain.

It was of course clear that these approaches would be linked with quite a range of difficulties, which had to be overcome before NOTES became ready for clinical application. An American working group elaborated a catalog of barriers that had to be overcome before clinical application: ${ }^{51}$

- access to peritoneal cavity;

- gastric (intestinal) closure;

Table 2 Organ-related advances in flexible endoscopy

\begin{tabular}{ll}
\hline Esophagus & $\begin{array}{l}\text { Ablation of Barrett mucosa, ESD, antireflux } \\
\text { interventions, stenting }\end{array}$ \\
ESD, full-thickness resection, stenting \\
Duodenum/small bowel & $\begin{array}{l}\text { Enteroscopy, hemostasis, biopsy } \\
\text { Colon }\end{array}$ \\
& Experimental: treatment of appendicitis \\
Liver & Stenting, drainage of the biliary system \\
& Experimental: treatment of cholecystitis \\
Pancreas & Stenting, biopsy, necrosectomy \\
\hline
\end{tabular}

Abbreviation: ESD, endoscopic submucosal dissection.
- prevention of infection;

- development of suturing device;

- development of anastomotic (nonsuturing device);

- spatial orientation;

- development of a multitasking platform to accomplish procedures;

- control of intraperitoneal hemorrhage;

- management of iatrogenic intraperitoneal complications;

- physiologic untoward events;

- compression syndromes;

- and training other providers.

Numerous studies exist concerning access to the abdominal cavity. ${ }^{52} \mathrm{Up}$ to now, the transgastric route is still preferred as compared to the transrectal entry, since the risk of contamination and the consequences of a secondary leakage appear to be lower. However, in the last few years, sophisticated new techniques were developed to make the transrectal approach relatively safe ${ }^{53}$ and made it more attractive, in particular for colonic resections. ${ }^{54}$ The transvaginal approach is something like a standard in rigid NOTES for cholecystectomy, but not as widely used in flexible NOTES. Most remarkably the transurethral approach - which certainly is extremely favorable in regards to sterility and wound closure - never found major interest for surgeons or interventional gastroenterologists.

The next barrier that has not yet been overcome is the development of a multitasking platform or the "super-endoscope", respectively. Almost every major provider of flexible endoscopes presented experimental devices such as the R-scope or the EndoSamurai from Olympus Corporation (Tokyo, Japan), or the Anubiscope from Karl Storz (Tuttlingen, Germany), just to name a few; and in addition several reports were published on laboratory devices such as the highly versatile single port system of our own group, ${ }^{55}$ but none of them ever achieved clinical maturity. Currently, the Master from the Technical University of Singapore ${ }^{56}$ seems to be closest to clinical application, but the area of application shifted clearly from NOTES to endoluminal procedures. Similarly, the new Endomina system is primarily designed for endoluminal interventions rather than NOTES. ${ }^{57}$ Obviously, another few years are required of intensive laboratory work till suitable platforms are available (Figure 10). ${ }^{58}$

Likewise, the development of suturing devices or solutions for endoluminal anastomoses is less than satisfying. Severe intraoperative bleedings are still as difficult to manage as 8 years ago. Accordingly, the list of clinical experience in NOTES is short. 


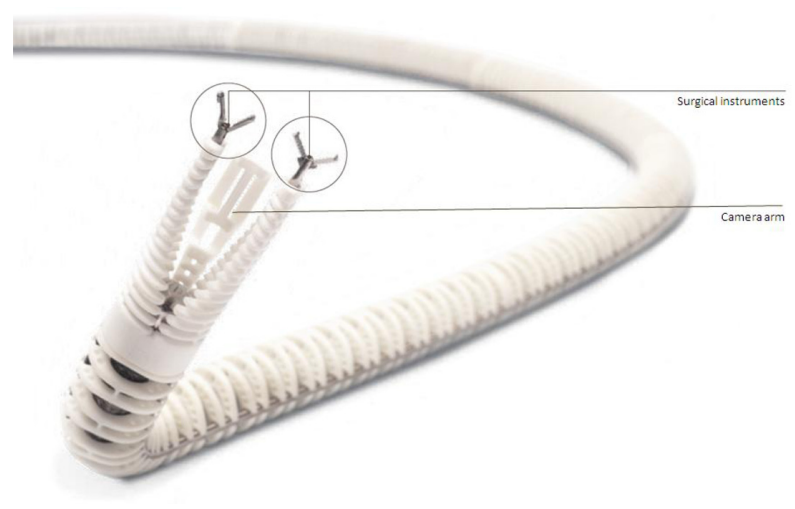

Figure 10 Experimental platform for scarless surgery developed by MiMed/TU München.

Notes: The system is mounted to a commercially available two-channel endoscope. Note the two actor arms. The third one is designed for an additional camera.

Abbreviation: MiMed/TU München, Institute of Micro Technology and Medical Device Technology/Technische Universität München.

\section{First clinical NOTES procedure}

Peritoneoscopy was the first procedure that was performed using the NOTES approach in $2008 .^{59}$ In 2010, a report appeared about 27 transgastric cholecystectomies ${ }^{60}$ and in 2013, about 14 transgastric appendectomies. ${ }^{61}$ Neither of these indications gained major acceptance up to now.

POEM in achalasia is the only pure NOTES application that is really on the threshold to become a competitor to conventional laparoscopic myotomy. First performed by Inoue in humans, ${ }^{62}$ it is now under evaluation all over the world. Initial reports indicate good short-term results. Major complications are rare, and the functional outcome is convincing. The theoretical advantages of POEM are self-evident, in particular the case of hypermotile achalasia, but the questions of recurrence and of postoperative acid reflux induction are still open. Nevertheless, POEM is a very good example of how the shift of traditional therapeutic paradigms can make NOTES feasible, independent of sophisticated new instruments and tools. The further development of NOTES depends, of course, upon technological innovation, but the specific input of the users to modify and to adapt their approaches is another important aspect.

\section{Conclusion}

Flexible endoscopic surgery has developed rapidly in the last few years due to the availability of innovative tools and the elaboration of new endoscopic procedures. However, some ideas have not (yet) become reality. In particular, the expected NOTES revolution has not occurred up to now. Evidently, the severity of technological barriers, which have been precisely defined in the beginning of the NOTES hype, was completely underestimated. However, technological barriers can be overcome, and the intensive research and development has already led to positive spin-off tools that greatly stimulate flexible endoscopic surgery. There are many reasons to assume that flexible surgery will play an equivalent role to classic surgery in interventional medicine.

\section{Disclosure}

The authors report no conflicts of interest in this work.

\section{References}

1. Cho WY, Jang JY, Lee DH, The Endoscopic Technology and Investigation Study Group. Recent advances in image-enhanced endoscopy. Clin Endosc. 2011;44:65-75.

2. Song J, Zhang J, Wang J, et al. Meta-analysis of the effects of endoscopy with narrow band imaging in detecting dysplasia in Barrett's esophagus. Dis Esophagus. In press 2014.

3. Borovicka J, Fischer J, Neuweiler J, et al. Autofluorescence endoscopy in surveillance of Barrett's esophagus: a multicenter randomized trial on diagnostic efficacy. Endoscopy. 2006;38(9):867-872.

4. Gupta A, Attar BM, Koduru P, Muralli AR, Go BT, Agarwal R. Utility of confocal laser endomicroscopy in identifying high-grade dysplasia and adenocarcinoma in Barrett's esophagus: a systematic review and meta-analysis. Eur J Gastroenterol Hepatol. 2014;26(4):369-377.

5. Shah RJ, Smolkin M, Yen R, et al. A multicentre, US experience of single-balloon, double-balloon, and rotational overtube-assisted enteroscopy ERCP in patients with surgically altered pancreaticobiliary anatomy (with video). Gastrointest Endosc. 2013;77(4):593-600.

6. Kantsevoy SV, Adler DG, Conway JD, et al. Endoscopic mucosal resection and endoscopic submucosal dissection. Gastrointest Endosc. 2008;68(1):11-18.

7. Isomoto H, Shikuwa S, Yamaguchi N, et al. Endoscopic submucosal dissection for early gastric cancer: a large-scale feasibility study. Gut. 2009;58(3):331-336.

8. Nishiyama N, Mori H, Kobara H, et al. Efficacy and safety of overthe-scope clip: including complications after endoscopic submucosal dissection. World J Gastroenterol. 2013;19(18):2752-2760.

9. Fujishiro M, Yahagi N, Nakamura M, et al. Successful outcomes of a novel endoscopic treatment for GI tumors: endoscopic submucosal dissection with a mixture of high-molecular-weight hyaluronic acid, glycerin, and sugar. Gastrointest Endosc. 2006;63(2):243-249.

10. Yamashina T, Ishihara R, Nagai $K$, et al. Long-term outcome and metastatic risk after endoscopic resection of superficial esophageal squamous cell carcinoma. Am J Gastroenterol. 2013;108(4):544-551.

11. Kumano I, Ishihara M, Nakamura S, et al. Endoscopic submucosal dissection for pig esophagus by using photocrosslinkable chitosan hydrogel as submucosal fluid cushion. Gastrointest Endosc. 2012;75(4): 841-848.

12. Al-Taie OH, Bauer Y, Dietrich CG, Fischbach W. Efficacy of submucosal injection of different solutions inclusive blood components on mucosa elevation for endoscopic resection. Clin Exp Gastroenterol. 2012;5:43-48

13. Meining A, Schneider A, Roppenecker D, Lüth T. A new instrument for endoscopic submucosal dissection (with videos). Gastrointest Endosc. 2013;77(4):654-657.

14. Yano T, Ono H, Doi T, et al. Endoscopic submucosal dissection using a new scissors-type electrosurgical knife: a first-in-human feasibility study. Endoscopy. 2014;46(9):754-757.

15. Chung H, Dhumane P, Liu KH, Donatelli G, Dallemagne B, Marescaux J. Endoscopic submucosal dissection with a novel traction method using a steerable grasper: a feasibility study in a porcine model. Surg Innov. 2014;21(1):5-10

16. Bhat YM, Hegde S, Knaus M, Solomon J, Kochman ML. Transluminal endosurgery: novel use of endoscopic tacks for the closure of access sites in natural orifice transluminal endoscopic surgery (with videos). Gastrointest Endosc. 2009;69(6):1161-1166. 
17. Fritscher-Ravens A, Hampe J, Grange P, et al. Clip closure versus endoscopic suturing versus thoracoscopic repair of an iatrogenic esophageal perforation: a randomized, comparative, long-term survival study in a porcine model (with videos). Gastrointest Endosc. 2010;72(5):1020-1026.

18. Schurr MO, Hartmann C, Ho CN, Fleisch C, Kirschniak A. An over-thescope clip (OTSC) system for closure of iatrogenic colon perforations: results of an experimental survival study in pigs. Endoscopy. 2008;40:584-588.

19. von Renteln D, Schmidt A, Vassiliou MC, Rudolph HU, Gieselmann M, Caca K. Endoscopic closure of large colonic perforations using an over-the-scope clip: a randomized controlled porcine study. Endoscopy. 2009;41(6):481-486

20. Arezzo A, Kratt T, Schurr MO, Morino M. Laparoscopic-assisted transgastric cholecystectomy and secure endoscopic closure of the transgastric defect in a survival porcine model. Endoscopy. 2009;41(9):767-772.

21. Gubler C, Bauerfeind P. Endoscopic closure of iatrogenic gastrointestinal tract perforations with the over-the-scope clip. Digestion. 2012;85(4):302-307.

22. Schlag C, Wilhelm D, von Delius S, Feussner H, Meining A. EndoResect study: endoscopic full-thickness resection of gastric subepithelial tumors. Endoscopy. 2013;45(1):4-11.

23. Meister T, Kuhlgatz J, Floer M. Over-the-Scope Clip (OTSC) application as rescue therapy for postoperative enterocutaneous fistula closure. Acta Chir Belg. 2014;114(1):87-89.

24. Mennigen R, Colombo-Benkmann M, Senninger N, Laukoetter M. Endoscopic closure of postoperative gastrointestinal leakages and fistulas with the Over-the-Scope Clip (OTSC). J Gastrointest Surg. 2013;17(6):1058-1065.

25. Schmidt A, Riecken B, Damm M, Cahyadi O, Bauder M, Caca K. Endoscopic removal of over-the-scope clips using a novel cutting device: a retrospective case series. Endoscopy. 2014;46(9):762-766.

26. Huang R, Pan Y, Hui N, et al. Polysaccharide hemostatic system for hemostasis management in colorectal endoscopic mucosal resection. Dig Endosc. 2014;26(1):63-68.

27. Khashab MA, Saxena P, Valeshabad AK, et al. Novel technique for submucosal tunnelling and endoscopic resection of submucosal tumors (with video). Gastrointest Endosc. 2013;77(4):646-648.

28. Menon L, Buscaglia JM. Endoscopic approach to subepithelial lesions. Ther Adv Gastroenterol. 2014;7(3):123-130.

29. Ye LP, Zhang Y, Mao XL, Zhu LH, Zhou X, Chen JY. Submucosal tunneling endoscopic resection for small upper gastrointestinal subepithelial tumors originating from the muscularis propria layer. Surg Endosc. 2014;28:524-530.

30. Xu MD, Cai MY, Zhou PH, et al. Submucosal tunnelling endoscopic resection: a new technique for treating upper GI submucosal tumors originating from the muscularis propria layer (with videos). Gastrointest Endosc. 2012;75(1):195-199.

31. Wiersema MJ, Sandusky D, CarrR, WiersemaLM,ErdelWC, FrederickPK. Endosonography-guided cholangiopancreatography. Gastrointest Endosc. 1996;43(2 pt 1):102-106.

32. Sarkaria S, Lee HS, Gaidhane M, Kahaleh M. Advances in endoscopic ultrasound-guided biliary drainage: a comprehensive review. Gut Liver. 2013;7(2):129-136.

33. Alvarez-Sánchez MV, Jenssen C, Faiss S, Napoléon B. Interventional endoscopic ultrasonography: an overview of safety and complications. Surg Endosc. 2014;28:712-734.

34. Becker V, Huber W, Meining A, et al. Infected necrosis in severe pancreatitis - combined nonsurgical multi-drainage with directed transabdominal high-volume lavage in critically ill patients. Pancreatology. 2009;9(3):280-286.

35. Seewald S, Ang TL, Teng KY, et al. Endoscopic ultrasound-guided drainage of abdominal abscesses and infected necrosis. Endoscopy. 2009;41(2):166-174.

36. Gornals JB, Loras C, Mast R, Botargues JM, Busquets J, Castellote J Endoscopic ultrasound-guided transesophageal drainage of a mediastinal pancreatic pseudocyst using a novel lumen-apposing metal stent. Endoscopy. 2012;44(Supp1 2):E211-E212.
37. Ross AS, Irani S, Gan SI, et al. Dual-modality drainage of infected and symptomatic walled-off pancreatic necrosis: long-term clinical outcomes. Gastrointest Endosc. 2014;79(6):929-935.

38. Weber A, Feussner H, Winkelmann F, Siewert JR, Schmid RM, Prinz C. Long-term outcome of endoscopic therapy in patients with bile duct injury after cholecystectomy. J Gastroenterol Hepatol. 2009;24(5): 762-769.

39. Nagaraja V, Eslick GD, Cos MR. Endoscopic stenting versus operative gastrojejunostomy for malignant gastric outlet obstruction-a systematic review and meta-analysis of randomized and non-randomized trials. J Gastrointest Oncol. 2014;5(2):92-98.

40. Dormann A, Meisner S, Verin N, Wenk Lang A. Self-expanding metal stents for gastroduodenal malignancies: systematic review of their clinical effectiveness. Endoscopy. 2004;36(6):543-550.

41. Khashab M, Alawad AS, Shin EJ, et al. Enteral stenting versus gastrojejunostomy for palliation of malignant gastric outlet obstruction. Surg Endosc. 2013;27(6):2068-2075.

42. Roy A, Kim M, Christein J, Varadarajuli S. Stenting versus gastrojejunostomy for management of malignant gastric outlet obstruction: comparison of clinical outcomes and costs. Surg Endosc. 2012;26(11):3114-3119.

43. Kaindlstorfer A, Koch OO, Berger J, Uwe Asche K, Pointner R. Full-thickness gastroplication for the treatment of gastroesophageal reflux disease: short-term results of a feasibility clinical trial. Surg Laparosc Endosc Percutan Tech. 2012;22(6):503-508.

44. Petersen RP, Filippa L, Wassenaar EB, Martin AV, Tatum R, Oelschlager BK. Comprehensive evaluation of endoscopic fundoplication using the EsophyX ${ }^{\mathrm{TM}}$ device. Surg Endosc. 2012;26:1021-1027.

45. Schwartz MP, Schreinemakers JRC, Smout AJPM. Four-year follow-up of endoscopic gastroplication for the treatment of gastroesophageal reflux disease. World J Gastrointest Pharmacol Ther. 2013;4(4): 120-126.

46. Yew KC, Chuah SK. Antireflux endoluminal therapies: past and present. Gastroenterol Res Pract. 2013;2013:481417.

47. Liu B, Feng J, Ma S. Endoscopic retrograde appendicitis treatment (Erat): a multicentre retrospective study in China. Gastrointest Endosc. 2013;77:AB146

48. Wilhelm D, von Delius S, Burian M, et al. Simultaneous use of laparoscopy and endoscopy for minimally invasive resection of gastric subepithelial masses - analysis of 93 interventions. World J Surg. 2008;32:1021-1028.

49. Wilhelm D, von Delius S, Weber L, et al. Combined laparoscopicendoscopic resections of colorectal polyps: 10-year experience and follow-up. Surg Endosc. 2009;23(4):688-693.

50. Heo J, Jeon SW. Hybrid natural orifice transluminal endoscopic surgery in gastric subepithelial tumors. World $J$ Gastrintest Endosc. 2013;5(9):428-432.

51. Rattner D, Kalloo A, the SAGES/ASGE Working Group on Natural Orifice Translumenal Endoscopic Surgery. ASGE/SAGES Working Group on Natural Orifice Transluminal Endoscopic Surgery. Surg Endosc. 2006;20:329-333.

52. von Delius S, Gillen S, Doundoulakis E, et al. Comparison of transgastric access techniques for natural orifice transluminal endoscopic surgery. Gastrointest Endosc. 2008;68(5):940-947.

53. Feussner H, Fiolka A, Schneider A, et al. Safe sigmoid access for natural orifice transluminal endoscopic surgery (NOTES). Colorectal Dis. 2011;13(Suppl 7):55-58.

54. Sylla P, Bordeianou LG, Berger D, et al. A pilot study of natural orifice transanal endoscopic total mesorectal excision with laparoscopic assistance for rectal cancer. Surg Endosc. 2013;27(9):3396-3405.

55. Can S, Fiolka A, Mayer H, et al. The mechatronic support system "HVSPS" and the way to NOTES. Minim Invasive Ther Allied Technol. 2008;17(6):341-345.

56. Chiu PW, Phee SJ, Wang Z, et al. Feasibility of full-thickness gastric resection using master and slave transluminal endoscopic robot and closure by Overstitch: a preclinical study. Surg Endosc. 2014;28(1): 319-324. 
57. Cauche H, Hiernaux M, Chau A. Endomina: the endoluminal universal robotized triangulation system: description and preliminary results in isolated pig stomach. Gastrointest Endosc. 2013;77:AB204-AB205.

58. Bergeles C, Yang GZ. From passive tool holders to microsurgeons: safer, smaller, smarter surgical robots. IEEE Trans Biomed Eng. 2014;61(5):1565-1576.

59. Hazey JW, Narula VK, Renton DB, et al. Natural-orifice transgastric endoscopic peritoneoscopy in humans: initial clinical trial. Surg Endosc. 2008;22(1):16-20.
60. Salinas G, Saavedra L, Agurto H, et al. Early experience in human hybrid transgastric and transvaginal endoscopic cholecystectomy. Surg Endosc. 2010;24(5):1092-1098.

61. Kaehler G, Schoenberg MB, Kienle P, Post S, Magdeburg R. Transgastric appendicectomy. Br J Surg. 2013;100(7):911-915.

62. Inoue $\mathrm{H}$, Minami $\mathrm{H}$, Kobayashi $\mathrm{Y}$, et al. Peroral endoscopic myotomy (POEM) for esophageal achalasia. Endoscopy. 2010;42(4): $265-271$.

\section{Publish your work in this journal}

Clinical and Experimental Gastroenterology is an international, peerreviewed, open access journal, publishing all aspects of gastroenterology in the clinic and laboratory, including: Pathology, pathophysiology of gastrointestinal disease; Investigation and treatment of gastointestinal disease; Pharmacology of drugs used in the alimentary tract;
Immunology/genetics/genomics related to gastrointestinal disease. This journal is indexed on CAS. The manuscript management system is completely online and includes a very quick and fair peer-review system. Visit http://www.dovepress.com/testimonials.php to read real quotes from published authors.

Submit your manuscript here: http://www.dovepress.com/clinical-and-experimental-gastroenterology-journal 